\title{
Article
}

\section{An exploratory randomised controlled trial comparing telephone and hospital follow-up after treatment for colorectal cancer}

Beaver, Kinta, Campbell, M., Williamson, Susan, Procter, D., Sheridan, J., Heath, J. and Susnerwala, S.

Available at http://clok.uclan.ac.uk/4761/

Beaver, Kinta ORCID: 0000-0002-6552-2323, Campbell, M., Williamson, Susan ORCID: 0000-0002-9635-4473, Procter, D., Sheridan, J., Heath, J. and Susnerwala, S. (2012) An exploratory randomised controlled trial comparing telephone and hospital follow-up after treatment for colorectal cancer. Colorectal Disease, 14 (10). pp. 1201-1209. ISSN 14628910

It is advisable to refer to the publisher's version if you intend to cite from the work. http://dx.doi.org/10.1111/j.1463-1318.2012.02936.x

For more information about UCLan's research in this area go to http://www.uclan.ac.uk/researchgroups/ and search for < name of research Group>.

For information about Research generally at UCLan please go to http://www.uclan.ac.uk/research/

All outputs in CLoK are protected by Intellectual Property Rights law, including Copyright law. Copyright, IPR and Moral Rights for the works on this site are retained by the individual authors and/or other copyright owners. Terms and conditions for use of this material are defined in the policies page. 


\title{
An exploratory randomized controlled trial comparing telephone and hospital follow-up after treatment for colorectal cancer
}

\author{
K. Beaver*, M. Campbell†, S. Williamson $\ddagger$ D. Procter§, J. Sheridan§, J. H \\ APPROVED \\ $¥$ School of Health, University of Central Lancashire, Preston, UK, §Surgical Directorate, Blackpool Teaching Hospit \\ 2 and - Rosemere Cancer Centre, Lancashire Teaching Hospitals NHS Foundation Trust, Preston, UK \\ 4 Received 8 September 201 I; accepted 31 October 20II; Accepted Article online XXXXXX 20XX
}

\begin{abstract}
Aim Following treatment for colorectal cancer it is common practice for patients to attend hospital clinics at regular intervals for routine monitoring, although debate persists on the benefits of this approach. Nurse-led telephone follow-up is effective in meeting information and psycho-social needs in other patient groups. We explored the potential benefits of nurse-led telephone follow-up for colorectal cancer patients.
\end{abstract}

Method Sixty-five patients were randomized to either telephone or hospital follow-up in an exploratory randomized trial.

Results The telephone intervention was deliverable in clinical practice and acceptable to patients and health professionals. Seventy-five per cent of eligible patients agreed to randomization. High levels of satisfaction were evident in both study groups. Appointments in the

5 hospital group were shorter (median $14.0 \mathrm{~min}$ ) than appointments in the telephone group (median $28.9 \mathrm{~min}$ ).
Patients in the telephone arm were more likely to raise concerns during consultations.

Conclusion Historical approaches to follow-up unsupported by evidence of effectiveness and efficiency are not sustainable. Telephone follow-up by specialist nurses may be a feasible option. A main trial comparing hospital and telephone follow-up is justified, although consideration needs to be given to trial design and practical issues related to the availability of specialist nurses at study locations.

Keywords Xxxxxx, Xxxxxx, Xxxxxx

\section{What is new in this paper?}

The study demonstrates that colorectal cancer patients do not need to attend busy hospital outpatient clinics for follow-up care. Specialist nurses can provide a quality service with high levels of patient satisfaction by telephoning patients at home and asking specific questions about physical and psycho-social function.

\section{Introduction}

Colorectal cancer (CRC) is the third most common cancer worldwide [1]. However, mortality rates have generally declined across Europe [2], reflecting improvements in treatment, detection of early stage cancers from screening programmes and/or improved symptom recognition $[3,4]$. Hence, increasing numbers of people live many years beyond diagnosis and treatment and need information and support to resume normal activities. The UK's National Cancer Survivorship Initiative (NCSI) has

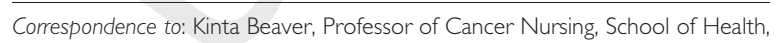
3 University of Central Lancashire, Preston, UK.

E-mail: kbeaver@uclan.ac.uk recognized the need to develop models of care that ensure that the needs of cancer survivors are met; improving self-care, care planning and making the best use of resources and technology [5].

Following treatment for CRC it is common practice for patients to return to hospital clinics at regular intervals over a number of years for routine monitoring aimed at detecting early recurrence. Debate has raged internationally on whether there are survival benefits to follow-up after curative CRC surgery, with little consensus on the best combination of tests/investigations to maximize outcome [6,7]. While work is ongoing to address these issues, other aspects of survivorship demand attention. Patients can be unaware that long-term side-effects are associated with treatment and they experience a host of 
physical and psychological problems [8]. Stoma patients may experience particular difficulties, with a negative impact on body image and quality of life [9-11], while debilitating bowel problems are also reported by patients treated with sphincter-saving surgery [12].

Specialist nurses can deliver a quality follow-up service, meeting psycho-social needs and providing adequate support with high levels of patient satisfaction and no physical or psychological detriment when compared with traditional doctor-led follow-up [13-17]. A randomized controlled trial (RCT) comparing hospital and nurse-led telephone follow-up for breast cancer patients reported positive findings in terms of satisfaction with service and meeting information needs [13]. This approach could be effective for CRC as the priority information needs of patients with breast cancer and CRC are reportedly similar [18]. Nurse-led telephone follow-up may reduce the burden on busy outpatient clinics, but there is limited evidence on the efficiency of these services. Economic evaluations of telephone follow-up are few and present a complex picture. Combining telephone follow-up with an educational group programme may result in cost savings [19], although telephone follow-up for breast cancer patients can be more expensive than traditional hospital follow-up if senior nurses spend longer on the telephone than doctors in hospital clinics [20].

Complex interventions that evaluate psycho-social and/or information-based approaches to care are difficult to evaluate. Hence, we conducted a series of studies that followed the Medical Research Council (MRC) Framework for Development and Evaluation of RCTs for complex interventions in health care [21]. Phase I (theoretical) and Phase II (modelling) involved qualitative and quantitative approaches that explored patient views on follow-up service provision and clarified components of the intervention $[22,23]$. This paper reports on Phase III (exploratory trial), a crucial component prior to a definitive RCT designed to test the delivery of the telephone intervention. The aim of this exploratory trial was to evaluate telephone follow-up, using a structured intervention, in terms of psychological morbidity, meeting information needs and satisfaction with information and service. In addition, the study was designed to collect data to determine appropriateness of inclusion/exclusion criteria and outcome measures, the acceptability of the intervention to patients and clinicians and the likely consent rate for recruitment to a main trial.

\section{Method}

This randomized pilot trial compared hospital and nurseled telephone follow-up for patients treated for CRC. We aimed to recruit approximately 60 patients, as recom- mended when estimating a particular parameter in a pilot study [24]. Eligible patients had a diagnosis of CRC, had completed treatment (surgery/radiotherapy/chemotherapy) with no evidence of recurrent disease, had access to a telephone, adequate hearing and were attending hospital outpatient consultations for routine monitoring. Recruitment took place at a large hospital in the north-west of England. Consecutive eligible patients were identified at the hospital clinics of four consultant surgeons and a colorectal nurse practitioner. The latter already provided a service to patients after treatment at nurse-led clinics, an expectation of the practitioner role. Clinical nurse specialists provided a service to patients at the time of diagnosis, on admission to hospital and at home following hospital discharge, and stoma care nurses attended to the needs of patients with a stoma. However, it was only the nurse practitioner who was involved in delivering the telephone intervention in this study. The study had approval from the National Research Ethics Service.

\section{Randomization}

Consenting individuals were randomized to either hospital or telephone follow-up by a computerized system. Group allocation was stratified by age ( $\leq 60$ years, $>60$ years) and gender. Allocation sequences were concealed until interventions were assigned. The analyst was blind to study group allocation. Participants randomized to the hospital arm were routinely reviewed at 6-weeks posttreatment, then 6-monthly intervals for 2 years and annually for a further 3 years and discharged to the care of their general practitioner (GP) after 5 years, unless complex or unresolved problems were evident. Hospital consultations could be conducted by consultant surgeons, registrars, more junior doctors or a colorectal nurse practitioner. The content and format of appointments in the hospital control arm was unaltered and clinicians focused on routine monitoring for detection of recurrent disease.

Participants randomized to telephone follow-up received telephone consultations from a colorectal nurse practitioner at the same prescribed intervals as participants in the hospital arm. Appointments were focused primarily on provision of information using a structured intervention to establish patient information needs. Appointment cards were sent, indicating the date and time of telephone appointments. These were registered on computerized hospital information systems in the same way as traditional hospital appointments so that medical records staff could retrieve patient notes prior to telephone clinics. Thirty minutes were allocated for telephone appointments $(20 \mathrm{~min}$ consultation time, 10 min administration), based on the mean time taken 
to deliver the telephone intervention in a previous trial of telephone follow-up for breast cancer patients [13]. The same nurse carried out all telephone consultations. As with hospital appointments, telephone clinic appointments were reimbursed to the hospital by the health authority.

\section{Telephone intervention}

The structured telephone intervention was developed from previous work $[13,18]$. Questions were asked relating to changes in condition, new or unresolved symptoms, information requirements about spread of disease, treatment and side-effects, genetic risk, sexual attractiveness, sexual function, self-care (diet, problems with wound/stoma, problems with bowels and urinary function, support groups, finances) and family concerns. All participants were asked if they had any other needs and concerns. Standard protocols related to routine tests and investigations (e.g. carcinoembryonic antigen blood levels, CT scan, colonoscopy) were unaltered. Four halfday sessions on the administration of the intervention were given, with regular feedback and de-briefing sessions throughout the study period. To monitor the integrity of the intervention, all telephone consultations were audiorecorded with patient consent. Any patient who presented with signs of recurrent disease (symptomatic or outcome of tests/investigations) was referred back to a hospital clinic and withdrawn from the telephone arm of the study.

\section{Measures}

Primary outcomes included psychological morbidity, meeting information needs and satisfaction with information and service. Secondary outcomes related to clinical investigations ordered, time to detection of recurrent disease and costs to patients. At this exploratory stage a formal economic evaluation was not conducted, although data were collected on patient out-of-pocket expenses.

Psychological morbidity was measured using the State-Trait Anxiety Inventory (STAI) and the General Health Questionnaire (GHQ). The STAI comprises 40 items measuring anxiety, differentiating between temporary anxiety (state, Yl) and long-standing anxiety reflected as a personality trait (trait, Y2). The GHQ focuses on a wider range of issues relating to psychological morbidity; we used the shortened 12 -item version (GHQ-12) to minimize patient burden. Both tools are self-administered and have been well validated $[25,26]$.

Patient information needs and satisfaction levels were recorded using questionnaires adapted from a survey of
CRC patients' follow-up needs and a satisfaction measure used in a lung cancer follow-up trial $[16,23]$. The items comprised tick-box responses, five-point Likert satisfaction and agreement scales and one overall satisfaction rating scale (ranging from 1 to 10 ). Questions were asked about health-care contacts between appointments and out-of-pocket expenses. All questionnaires were administered at baseline and at one additional time point, individually chosen to maximize the number of appointments that patients had between completion of measures. To capture the benefits of immediate recall, questionnaires were posted shortly after scheduled appointments.

Clinical outcomes for the hospital arm were recorded using a 'record of visit' form, including details on who patients saw at consultations, tests/investigations ordered, referrals made, clinical examinations conducted and indications of recurrent disease. For the telephone group the nurse completed an intervention guide on areas of concern discussed during telephone consultations, tests/investigations ordered, referrals made and any indications of recurrent disease. This information was cross-checked by a researcher who listened to telephone consultation recordings and completed a proforma similar to the intervention guide. Any confirmed disease recurrences were closely monitored through hospital records and consultation with clinical staff. At study end a retrospective examination was made of all participants' case notes to check the accuracy of clinical data.

\section{Statistical analysis}

Analysis was by intention-to-treat. As this was a pilot study, analyses were mainly descriptive, and estimation of recruitment, protocol violation, attrition and data completion rates were important. Analysis of covariance was used to compare STAI, GHQ-12 and satisfaction with appointment scores at follow-up by group adjusted for baseline scores and estimate $95 \%$ confidence intervals for differences in adjusted means. The unpaired $t$-test was also used to compare satisfaction with appointment scores at follow-up by group, given that those in the telephone group had a different kind of appointment at follow-up. Fisher's exact test was also used to compare categorical outcomes by group. The results of any inferential comparisons should be interpreted with caution given that the study was not powered to detect statistically significant differences.

\section{Results}

Figure 1 shows the flow of participants through the trial. Ninety-eight patients were eligible for inclusion although eight had either not attended their appointments as 


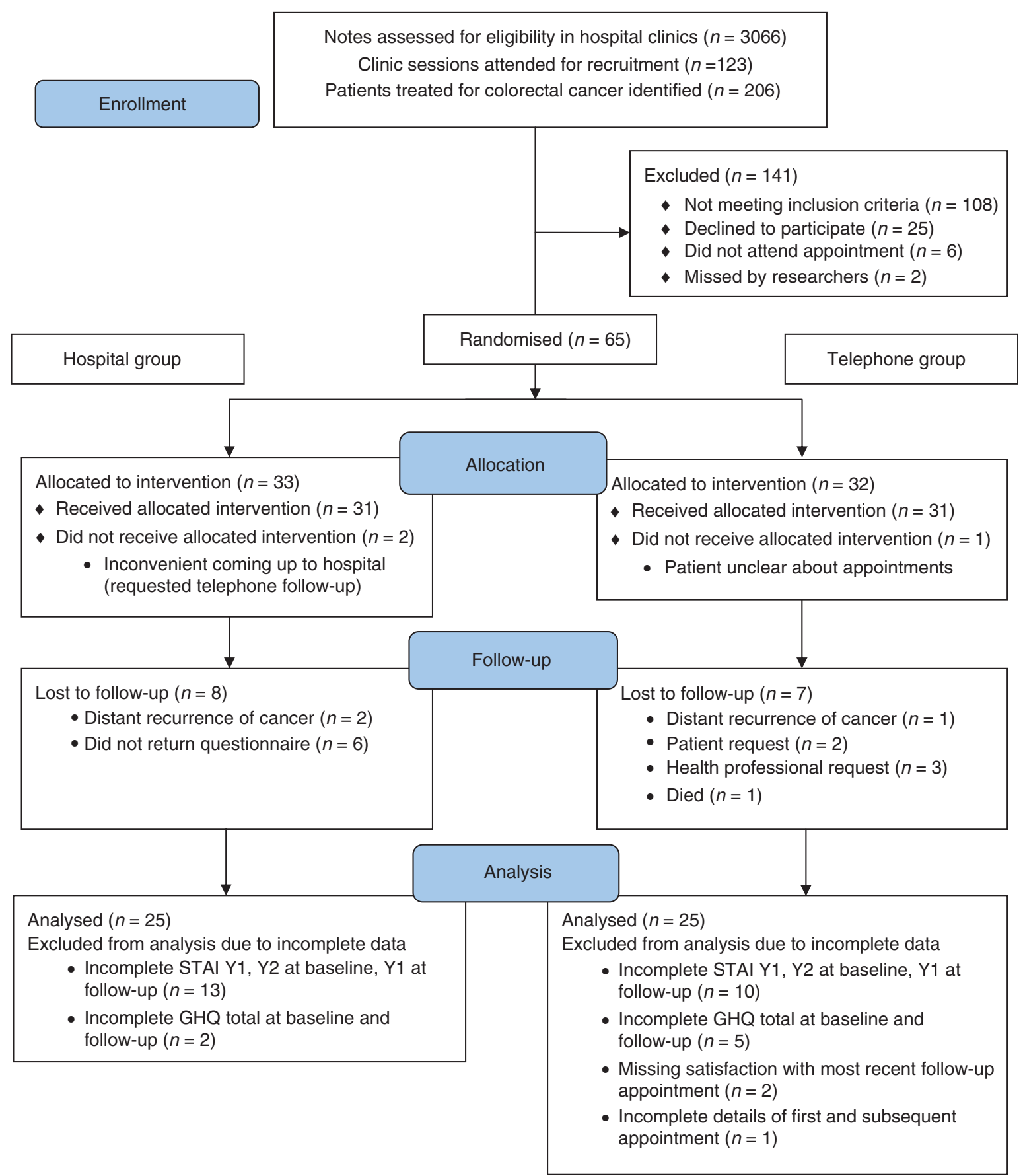

Figure I Flow of participants through the pilot trial [STAI, State-Trait Anxiety Inventory (Y1, temporary anxiety state; Y2, personality trait); GHQ-12, General Health Questionnaire (shortened 12-item version)].

scheduled or were missed by researchers. The study was discussed with the remaining 90 patients; 65 consented to participate $(72 \%)$. Of 65 patients randomized, only three did not receive the intervention as allocated and 15 (23\%) were lost to follow-up (Fig. 1). Patients remained in the study from 8 to 15 months (mean 12 months). A typical participant was male (58\%), married (64\%) and retired from work (88\%). Participants were a mean of 21 months from diagnosis and groups were reasonably balanced at baseline (Table 1).

Eight participants from the hospital arm (24\%) and seven from the telephone arm $(22 \%)$ did not provide follow-up data (Fig. 1). The four men and two women in the hospital arm who did not return questionnaires were 
Table I Baseline characteristics of participants.

\begin{tabular}{|c|c|c|c|c|}
\hline \multirow[b]{2}{*}{ Characteristic } & \multicolumn{2}{|c|}{$\begin{array}{l}\text { Hospital group } \\
(n=25)\end{array}$} & \multicolumn{2}{|c|}{$\begin{array}{l}\text { Telephone } \\
\text { group }(n=25)\end{array}$} \\
\hline & Mean & SD & Mean & SD \\
\hline \multirow[t]{2}{*}{ Age (years) } & 72.4 & 8.2 & 73.6 & 7.6 \\
\hline & Number & $\%$ & Number & $\%$ \\
\hline Aged over 60 & 22 & 88 & 22 & 88 \\
\hline \multicolumn{5}{|l|}{ Gender } \\
\hline Male & 13 & 52 & 16 & 64 \\
\hline Female & 12 & 48 & 9 & 36 \\
\hline \multicolumn{5}{|l|}{ Marital status } \\
\hline Married/cohabiting & 17 & 68 & 15 & 60 \\
\hline Divorced/separated & 2 & 8 & 4 & 16 \\
\hline Widowed & 5 & 20 & 4 & 16 \\
\hline Never married & 1 & 4 & 2 & 8 \\
\hline \multirow[t]{2}{*}{ Retired from work } & 22 & 88 & 22 & 88 \\
\hline & Mean & $\mathrm{SD}$ & Mean & SD \\
\hline $\begin{array}{l}\text { Time from diagnosis } \\
\text { (months) }\end{array}$ & 18.7 & 14.4 & 22.4 & 16.1 \\
\hline \multirow{2}{*}{$\begin{array}{l}\text { Time from first post- } \\
\text { treatment visit (months) }\end{array}$} & 12.3 & 15.3 & 17.0 & 16.0 \\
\hline & Number & $\%$ & Number & $\%$ \\
\hline Surgery & 25 & 100 & 25 & 100 \\
\hline Radiotherapy & 1 & 4 & 4 & 16 \\
\hline Chemotherapy & 9 & 36 & 5 & 20 \\
\hline \multicolumn{5}{|l|}{ Cancer location } \\
\hline Colon & 17 & 68 & 12 & 48 \\
\hline Rectum & 8 & 32 & 13 & 52 \\
\hline \multicolumn{5}{|l|}{ Stoma } \\
\hline Permanent & 5 & 20 & 9 & 36 \\
\hline Temporary & 0 & 0 & 1 & 4 \\
\hline Stoma now reversed & 2 & 8 & 5 & 20 \\
\hline No stoma & 18 & 72 & 10 & 40 \\
\hline
\end{tabular}

slightly younger (mean age 69 years) and not as far from diagnosis (mean 11 months). The one death recorded during the study was unrelated to CRC. Three participants (two hospital, one telephone) changed group during the study.

Not all participants provided complete data on the primary outcome measures. Only 12 (48\%) hospital and $15(60 \%)$ telephone participants provided complete data on the STAI at baseline and follow-up. No particular item appeared to give participants a problem. However, five hospital and one telephone participant answered at least 19 of the 20 'state' (Y1) questions but none of the 20 'trait' (Y2) questions at baseline. All but one of these participants answered at least 19/20 'state' questions at follow-up. Responses to the GHQ-12 were better: 23 (92\%) hospital and $20(80 \%)$ telephone participants provided complete data (Table 2). Mean and median scores for STAI state anxiety were appreciably higher in the hospital arm at follow-up (Cohen's $d=0.66$ ), and mean GHQ-12 score was slightly higher (Cohen's $d=0.11)$. There were no significant differences between groups at follow-up in STAI $(P=0.297)$ or GHQ-12 $(P=0.626)$.

Questions on information needs were answered by the majority at baseline and follow-up. Information about genetic risk and self-care were the most common information needs in each group at baseline (Table 3). By follow-up, this was still true for the telephone arm and at the same level. However, in the hospital arm information about genetic risk and sexual attractiveness were the most common needs but at a reduced level. The most noticeable difference between groups was the number of information needs raised by participants: in the telephone arm, 33 needs were raised at baseline and 30 at follow-up; in the hospital arm 32 were raised at baseline but only 16 were raised at follow-up. Only three

Table 2 Psychological morbidity by randomization group.

\begin{tabular}{|c|c|c|c|c|c|c|c|c|c|c|}
\hline \multirow[b]{2}{*}{ Measure } & \multicolumn{5}{|c|}{ Hospital group $(n=25)$} & \multicolumn{5}{|c|}{ Telephone group $(n=25)$} \\
\hline & No. & Mean & SD & Median & Range & No. & Mean & SD & Median & Range \\
\hline \multicolumn{11}{|l|}{ Baseline } \\
\hline STAI Y1 & 12 & 29.0 & 8.9 & 25 & $20-47$ & 15 & 28.5 & 8.1 & 27 & $20-42$ \\
\hline STAI Y2 & 12 & 35.9 & 13.2 & 32 & $22-63$ & 15 & 31.3 & 10.8 & 29 & $20-53$ \\
\hline GHQ-12 total & 23 & 1.4 & 1.8 & 1 & $0-6$ & 20 & 1.5 & 2.3 & 0 & $0-6$ \\
\hline \multicolumn{11}{|l|}{ Follow-up } \\
\hline STAI Y1* & 12 & 36.0 & 17.4 & 31 & $20-73$ & 15 & 27.9 & 9.8 & 24 & $20-50$ \\
\hline GHQ-12 total $\dagger$ & 23 & 1.3 & 2.7 & 0 & $0-10$ & 20 & 1.0 & 2.9 & 0 & $0-12$ \\
\hline
\end{tabular}

STAI, State-Trait Anxiety Inventory (Y1, temporary anxiety state; Y2, personality trait); GHQ-12, General Health Questionnaire (shortened 12 -item version).

*Analysis of covariance: $F=1.14$, d.f. $=1$ and $23, P=0.297 ; 95 \%$ CI for difference between adjusted means -3.5 to 11.1

$\dagger$ Analysis of covariance: $F=0.24$, d.f. $=1$ and $40, P=0.626 ; 95 \%$ CI for difference between adjusted means -1.1 to 1.8 
Table 3 Information needs by randomization group.

\begin{tabular}{|c|c|c|c|c|c|c|c|c|c|c|c|c|}
\hline & \multicolumn{6}{|l|}{ Baseline } & \multicolumn{6}{|l|}{ Follow-up } \\
\hline & \multicolumn{3}{|c|}{$\begin{array}{l}\text { Hospital group } \\
(n=25)\end{array}$} & \multicolumn{3}{|c|}{$\begin{array}{l}\text { Telephone group } \\
(n=25)\end{array}$} & \multicolumn{3}{|c|}{$\begin{array}{l}\text { Hospital group } \\
(n=25)\end{array}$} & \multicolumn{3}{|c|}{$\begin{array}{l}\text { Telephone group } \\
(n=25)\end{array}$} \\
\hline & $\begin{array}{l}\text { No. of } \\
\text { responses }\end{array}$ & $\begin{array}{l}\text { No. with } \\
\text { need }\end{array}$ & $\%$ & $\begin{array}{l}\text { No. of } \\
\text { responses }\end{array}$ & $\begin{array}{l}\text { No. with } \\
\text { need }\end{array}$ & $\%$ & $\begin{array}{l}\text { No. of } \\
\text { responses }\end{array}$ & $\begin{array}{l}\text { No. with } \\
\text { need }\end{array}$ & $\%$ & $\begin{array}{l}\text { No. of } \\
\text { responses }\end{array}$ & $\begin{array}{l}\text { No. with } \\
\text { need }\end{array}$ & $\%$ \\
\hline $\begin{array}{l}\text { Information about the } \\
\text { disease and whether } \\
\text { it had spread }\end{array}$ & 24 & 4 & 17 & 21 & 4 & 19 & 23 & 1 & 4 & 21 & 3 & 14 \\
\hline $\begin{array}{l}\text { Information about the } \\
\text { different types of } \\
\text { treatment, including } \\
\text { side-effects }\end{array}$ & 24 & 4 & 17 & 21 & 4 & 19 & 23 & 2 & 9 & 24 & 3 & 13 \\
\hline $\begin{array}{l}\text { Information about whether } \\
\text { children or other family } \\
\text { members are at risk }\end{array}$ & 23 & 10 & 43 & 21 & 8 & 38 & 23 & 5 & 22 & 24 & 7 & 29 \\
\hline $\begin{array}{l}\text { Information about how } \\
\text { treatment may have } \\
\text { affected feelings about } \\
\text { body andsexual } \\
\text { attractiveness }\end{array}$ & 23 & 4 & 17 & 20 & 6 & 30 & 22 & 5 & 23 & 23 & 4 & 17 \\
\hline $\begin{array}{l}\text { Information about caring } \\
\text { for self }\end{array}$ & 23 & 9 & 39 & 21 & 8 & 38 & 23 & 3 & 13 & 24 & 8 & 33 \\
\hline $\begin{array}{l}\text { Concerns about how } \\
\text { family are coping with } \\
\text { diagnosis }\end{array}$ & 24 & 0 & 0 & 21 & 2 & 10 & 23 & 0 & 0 & 23 & 3 & 13 \\
\hline Other information required & 21 & 1 & 4 & 17 & 1 & 6 & 22 & 0 & 0 & 22 & 2 & 10 \\
\hline
\end{tabular}

participants reported 'other' information needs. One participant wanted information about bowel function, which was included in the intervention, and two did not specify information needed.
Satisfaction with the most recent appointment was scored by all 50 participants at baseline and by all those in the hospital arm and 23 of those in the telephone arm at follow-up (Table 4 ). The mean score for satisfaction with

Table 4 Satisfaction with service and information provision by randomization group.

\begin{tabular}{|c|c|c|c|c|c|c|c|c|c|c|c|c|}
\hline & \multicolumn{6}{|l|}{ Baseline } & \multicolumn{6}{|l|}{ Follow-up } \\
\hline & \multicolumn{3}{|c|}{$\begin{array}{l}\text { Hospital group } \\
(n=25)\end{array}$} & \multicolumn{3}{|c|}{$\begin{array}{l}\text { Telephone group } \\
(n=25)\end{array}$} & \multicolumn{3}{|c|}{$\begin{array}{l}\text { Hospital group } \\
(n=25)\end{array}$} & \multicolumn{3}{|c|}{$\begin{array}{l}\text { Telephone group } \\
(n=25)\end{array}$} \\
\hline & $\begin{array}{l}\text { No. of } \\
\text { responses }\end{array}$ & Mean & SD & $\begin{array}{l}\text { No. of } \\
\text { responses }\end{array}$ & Mean & SD & $\begin{array}{l}\text { No. of } \\
\text { responses }\end{array}$ & Mean & SD & $\begin{array}{l}\text { No. of } \\
\text { responses }\end{array}$ & Mean & SD \\
\hline \multirow{2}{*}{$\begin{array}{l}\text { Satisfaction with most } \\
\text { recent appointment }{ }^{*}, \dagger\end{array}$} & 25 & 9.0 & 1.1 & 25 & 8.7 & 1.8 & 25 & 9.5 & 0.8 & 25 & 9.8 & 0.5 \\
\hline & & $n$ & $\%$ & & $n$ & $\%$ & & $n$ & $\%$ & & $n$ & $\%$ \\
\hline $\begin{array}{l}\text { Received all } / \text { most } \\
\text { information needed }\end{array}$ & 23 & 22 & 96 & 22 & 21 & 95 & 25 & 25 & 100 & 23 & 23 & 100 \\
\hline Had concerns or problems & 24 & 7 & 29 & 23 & 8 & 35 & 23 & 3 & 13 & 25 & 5 & 20 \\
\hline Mentioned concerns & 10 & 8 & 80 & 11 & 7 & 64 & 7 & 3 & 43 & 10 & 9 & 90 \\
\hline $\begin{array}{l}\text { Very satisfied/satisfied with } \\
\text { way concerns were addressed }\end{array}$ & 12 & 11 & 92 & 14 & 13 & 93 & 11 & 11 & 100 & 18 & 17 & 94 \\
\hline
\end{tabular}

*At follow-up, unpaired $t$-test: $t=-1.66$, d.f. $=39.6, P=0.104 ; 95 \%$ CI for difference between means -0.7 to 0.7 .

$\dagger$ At follow-up, analysis of covariance: $F=5.08$, d.f. $=1$ and $45, P=0.029 ; 95 \%$ CI for difference between adjusted means -0.8 to -0.04 . 
the most recent appointment was higher in the telephone arm (Cohen's $d=0.45)$. Unadjusted for baseline scores, there was no evidence of a difference in satisfaction between groups at follow-up $(P=0.104)$; adjusted for baseline scores, satisfaction was higher in telephone follow-up $(P=0.029)$. The most noticeable difference between the groups was in the mentioning of concerns at the follow-up appointment: $3 / 7$ hospital participants who answered the question did so compared with $9 / 10$ telephone participants, although the difference was not statistically significant (Fisher's exact $P=0.101$ ).

The two groups were similar at baseline in terms of numbers of contacts between appointments with health professionals in the previous 6 months. The groups were also similar at follow-up, with fewer contacting a GP or hospital doctor. In the hospital arm, nine had contacted a GP, ten a colorectal nurse and one a hospital doctor; in the telephone arm the numbers were eight, thirteen and three respectively. There were no noticeable differences in the numbers of participants in the two groups in terms of blood tests or colonoscopies ordered, although CT scans were more likely to be ordered in the hospital (14/25, $56 \%)$ than the telephone $(10 / 24,42 \%)$ arm. The difference was not statistically significant but the sample size was small.

There was a clear difference between groups for duration of appointment. The median duration of hospital appointments was $14.0 \mathrm{~min}$ (range 2.3-58.0) compared 7 with a median of 28.9 min (range 6.1-48.3; MannWhitney $U=136.0, P=0.001$ ) for telephone appointments. Within the hospital arm, a nurse conducted 12 of the face-to-face appointments (median $24.0 \mathrm{~min}$, range 8.8-33.0) and two telephone appointments (34.6 and $58.0 \mathrm{~min}$ ); the other 11 appointments were with hospital doctors (median 4.0 min, range 2.3-13.8).

Two hospital participants and one telephone participant had a recurrence during the study. All three occurred in asymptomatic male patients and were detected by routine investigations ordered at hospital/telephone appointments (CT scan in all cases). Time to detection of recurrence was estimated based on the date on which the scan showed an abnormality to the date the patient was informed of the diagnosis of recurrence. For the telephone participant (age 72 years) it was 8 weeks to confirmation of metastases in a retrocaval node. For the two hospital participants, time to detection of recurrence was 7 weeks for one individual with lung metastases (81 years) and 8 weeks for an individual with liver metastases ( 59 years).

At baseline, patients reported that it took a median of $22.5 \mathrm{~min}$ (range 10-60) to get to the hospital appointment from home. For the hospital arm this was similar at 8 the follow-up time point (median $30 \mathrm{~min}$ ). The majority reported travelling to hospital appointments in their own car or a friend's/relative's car (63.1\% at baseline, $65.2 \%$ for the hospital arm at follow-up). Other forms of transport included bus, taxi and hospital transport. For those who used public transport the cost was reported as a median of $£ 3$ (€3.42) at baseline (range $£ 1-18$, $€ 1.14$ 20.51 ) and $£ 8$ (€9.11) at follow-up (range $£ 5-11, € 5.70$ 12.53). Only four participants reported having to take time out of work for their hospital appointments at baseline and one at the follow-up time point. However, the majority reported being accompanied to hospital appointments by a relative/friend at baseline $(73.9 \%)$, slightly reduced at follow-up (56.5\%).

\section{Discussion}

This study demonstrates that telephone follow-up by specialist nurses is an acceptable and feasible approach to providing follow-up care for CRC patients and inclusion criteria appear appropriate. The intervention was relevant; no questions were considered redundant or unsuitable. Early indications are that telephone follow-up can be successfully incorporated into clinical practice within current resources. While the best combination of tests and investigations for maximizing patient outcomes remains unclear, telephone follow-up is one means of meeting psycho-social needs and providing patients with the information and support they need to live well following diagnosis.

Although it is unlikely that specialist nurses could provide follow-up care for all patients on completion of treatment, they could take responsibility for a significant cohort who had a preference for being telephoned at home. In this study $75 \%$ agreed to randomization, indicating that patients were agreeable to their consultation being carried out by a specialist nurse rather than a doctor. A recent study comparing nurse- and doctor-led follow-up after rectal cancer surgery found that patient satisfaction was equally as high for nurses and doctors [27]. If telephone support is equivalent to hospital support, with no physical or psychological detriment, then a negotiated approach offering patients a choice of follow-up care provision could be introduced.

Outcome measures appeared to be appropriate, although there were missing data for 'trait' (Y2) questions on STAI. We are not clear why this was the case and may have resulted from administrative error; more detailed records would need to be kept in any future trial. Participants did not have raised anxiety levels if they were telephoned, foregoing face to face contact with a hospital doctor. This would justify a RCT with a noninferiority or equivalence design in future research. Telephone participants raised more concerns. Arguably, 
information needs were met at hospital visits and therefore patients did not have any concerns. Alternatively, patients may not have been comfortable raising concerns in busy hospital clinics. If clinicians rely on patients to initiate discussion of psycho-social issues then problems may not be addressed [28].

Appointments with a nurse were longer than appointments with a doctor, irrespective of study group. Appointments with hospitals doctors were of short duration (mean $94.8 \mathrm{~min}$ ). This clearly has cost implications. Although patients in the telephone group saved time and travelling costs, more evidence is needed on whether this is a costeffective approach for the health service. It was more likely that patients would mention their concerns during telephone consultations, probably as a result of being asked specific questions, and this may have extended consultations. As this was a pilot study, patients were not followed up over an extended time period, and we are uncertain if appointment duration reduces over time once nurses are familiar with the intervention and initial concerns and information needs are addressed.

A limitation of the study was that the same nurse conducted some of the hospital appointments and all the telephone appointments. Although the nurse only used the structured telephone intervention with patients randomized to the telephone arm, contamination is possible and would need to be avoided in a main trial. Resources were not available to carry out a multicentre study with a number of different specialist nurses. However, there was value in one nurse being involved in both arms of the study at the pilot stage in providing useful feedback on the two approaches and training requirements to inform the main study. A design that involves sequential rollout of the intervention may be a suitable and practical design if there is a shortfall in the number of nurses required to eliminate contamination between study groups.

In the current economic climate it is unlikely we can sustain historical approaches to follow-up that are not supported by evidence of effectiveness and efficiency. The telephone intervention was acceptable to both patients and health professionals and was deliverable in practice. A main trial of the intervention is justified with an economic evaluation, preferably with an equivalence or non-inferiority design.

\section{Acknowledgements}

We would like to thank Sandra Foster for her assistance with data collection. Thanks are also expressed to the consultant surgeons at the study location who granted access to their clinics for the purpose of recruitment. Our thanks are also expressed to all patients who participated in this study.

\section{Funding}

This study was financially supported by a small project grant from Cancer Research UK.

\section{Conflict of interest}

The authors declare no potential conflicts of interest.

\section{References}

1 Parkin DM, Bray F, Ferlay J et al. Global cancer statistics, 2002. CA Cancer J Clin 2005; 55: 74-108.

2 Ferlay J, Parkin DM, Steliarova-Foucher E. Estimates of cancer incidence and mortality in Europe in 2008. Eur J Cancer 2008; 46: 765-81.

3 Center MM, Jemal A, Smith RA et al. Worldwide variations in colorectal cancer. CA Cancer J Clin 2009; 59: 366-78.

4 Schurer W, Kanavos P. Colorectal cancer management in the United Kingdom: current practice and challenges. Eur J Health Econ 2010; 10(Suppl 1): S85-90.

5 Department of Health. (2010) The National Cancer Survivorship Initiative Vision. Department of Health, Macmillan Cancer Support and NHS Improvement, London, UK.

6 Papagrigoriadis S. Follow-up of patients with colorectal cancer: the evidence is in favour but are we still in need of a protocol. Int J Surg 2007; 5: 120-8.

7 Jeffery GM, Hickey BE, Hider P. Follow-up strategies for patients treated for non-metastatic colorectal cancer. Cochrane Database Syst Rev 2007; ?!?! ???-???, Issue 1. Art. No.: CD002200. DOI: 10.1002/14651858.CD002200.pub2. 10

8 Macmillan Cancer Support. (2009) It's No Life: Living with the Long Term Effects of Cancer. Macmillan Cancer Support, London, http://www.macmillan.org.uk/Documents/Getinvolved/Campaigns/Campaigns/itsnolife (accessed April 2011).

9 Brown H, Randle J. Living with a stoma: a review of the literature. J Clin Nurs 2005; 14: 74-81.

10 Rozmovits L, Rose P, Ziebland S. In the absence of evidence, who chooses? A qualitative study of patients' needs after treatment for colorectal cancer J Health Serv Res Policy 2004; 9: 159-64.

11 Lynch BM, Hawkes AL, Steginga SK et al. Stoma surgery for colorectal cancer: a population based study of patient concerns. J Wound Ostomy Continence Nurs 2008; 35: 424-8.

12 Nikoletti S, Young J, Levitt M et al. Bowel problems, selfcare practices and information needs of colorectal cancer survivors at 6 to 24 months after sphincter-saving surgery. Cancer Nurs 2008; 31: 389-98.

13 Beaver K, Tysver-Robinson D, Campbell M et al. Comparing hospital and telephone follow-up after treatment for breast cancer: a randomised equivalence trial. $\mathrm{Br}$ Med J 2009; 338: a3147.

14 Knowles G, Sherwood L, Dunlop MG et al. Developing and piloting a nurse-led model of follow-up in the multidisciplinary management of colorectal cancer. Eur J Oncol Nurs 2007; 11: 212-23. 
15 Wells M, Donnan PT, Sharp L et al. A study to evaluate nurse-led on-treatment review for patients undergoing radiotherapy for head and neck cancer. J Clin Nurs 2007; 17: 1428-38.

16 Moore S, Corner J, Haviland J et al. Nurse led follow up and conventional medical follow up in management of patients with lung cancer: randomized trial. $\mathrm{Br} \operatorname{Med} J$ 2002; 325: 1145-52.

17 Cox K, Wilson E. Follow-up for people with cancer: nurseled services and telephone interventions. J Adv Nurs 2003; 43: 51-61.

18 Beaver K, Booth K. Information needs and decision making preferences: comparing findings for gynaecological, breast and colorectal cancer. Eur J Oncol Nurs 2007; 11: 409-16.

19 Kimman ML, Dirksen CD, Voogd AC et al. Economic evaluation of four follow-up strategies after curative treatment for breast cancer: results of an RCT. Eur J Cancer 2011; 47: 1175-85.

20 Beaver K, Hollingworth W, McDonald R et al. Economic evaluation of a randomized clinical trial of hospital versus telephone follow-up after treatment for breast cancer. $\mathrm{Br} J$ Surg 2009; 96: 1406-15.
21 Medical Research Council. (2000) A Framework for Development and Evaluation of RCTs for Complex Interventions to Improve Health. Medical Research Council, London.

22 Beaver K, Latif S, Williamson S et al. An exploratory study of the follow-up care needs of patients treated for colorectal cancer. J Clin Nurs 2010; 19: 3291-330.

23 Beaver K, Wilson C, Procter D et al. Colorectal cancer follow-up: patient satisfaction and amenability to telephone after care. Eur J Oncol Nurs 2011; 15: 23-30.

24 Lancaster GA, Dodd S, Williamson PR. Design and analysis of pilot studies: recommendations for good practice. J Eval Clin Pract 2004; 10: 307-12.

25 Spielberger CD. (1983) State-Trait Anxiety Inventory. Consulting Psychologists Press Inc., ????.

26 Goldberg DP. (1978) Manual of the General Health Questionnaire. NFER Nelson, Windsor.

27 Strand E, Nygren I, Bergkvist L, Smedh K. Nurse or surgeon follow-up after rectal cancer: a randomized trial. Colorectal Dis 2011; 13: 999-1003.

28 Taylor S, Harley C, Campbell LJ et al. Discussion of emotional and social impact of cancer during outpatient oncology consultations. Psycho-Oncology 2011; 20: 242-51. 